\title{
ACADEMICIAN VITALIY IVANOVICH STAROSTENKO - 85th ANNIVERSARY
}

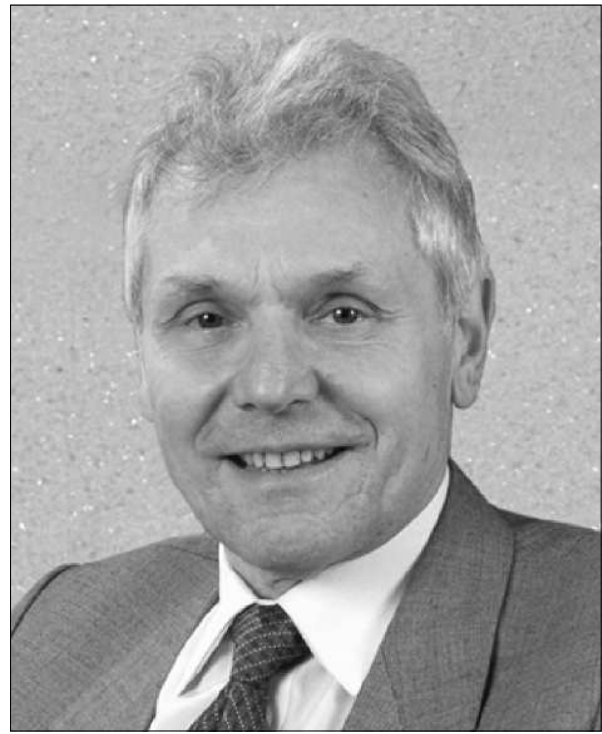

In April this year Vitaliy I. Starostenko, a famous Ukrainian scientist-geophysicist, has celebrated his 85th Aniversary. He is a recognized expert in the areas of the theory of potential fields interpretation, automated processing and interpretation of gravimetric and magnetometric data, theories and methodology of solving of ill-posed problems in geophysics, and density models of the Earth's crust and upper mantle formation.

Vitaliy I. Starostenko is a Candidate of Technical Sciences (1966), Doctor of Sciences in Physics and Mathematics (1977), Professor (1984), Corresponding member (1985) of the National Academy of Sciences of Ukraine (NASU), Full Member of NASU (1990), Full Member of the New York Academy of Sciences (1995). He is a Head of the Deep Processes of the Earth and Gravity Department of the Institute of Geophysics of NASU (since 1976), Deputy Director (19751991) and Director of this institute (since 1992), He served as a Deputy Academician-Secretary (1978-1988) and Academician-Secretary (1988-
2004) of the Geosciences Department of NASU Member of the Presidium of NASU (1988-2004). Among his awards and recognitions, are the State Prize of Ukraine in Science and Technology (1984, 1995), the honorary title "Honored Scientist and Technologist of Ukraine" (1997), the Cabinet of Ministers research award (2014) and the S.I. Subbo tin Award of the NASU (2015).

Vitaliy I. Starostenko was born on April 13, 1935 in Kyiv, in the family of engineers-technologists in the sugar refining industry. He received his high-school education in the city of Kyiv, and then entered Kyiv State University, which he graduated in 1958, with a Diploma of engineer geologist-geophysicist. Then Vitaliy I. Starostenko had worked for three years as an engineer-operator, engineer-interpreter and a field group leader in the Kyiv geophysics exploratory expedition "Ukrgeophisrozvidka Trust".

The experience in these gravimetric measurements and their further interpretation became an impetus, which inspired Vitaliy I. Starostenko in 1961 to enter the Postgraduate School at the Institute of Geophysics of the Academy of Sciences of UkrSSR. His scientific advisor was one of the most famous geophysicists (both theoretician and experimentalist) in the area of interpretation of potential fields - I.A. Balabushevitch. Since that time, all Vitaliy I. Starostenko's following life path was closely related to the Institute of Geophysics of the National Academy of Sciences of Ukraine, where he rose from a Junior Researcher to the Director of the Institute.

Scientific interests of Vitaliy I. Starostenko were, first of all, connected to the theory of potential fields interpretation. Vitaliy I. Starostenko defended the Thesis of the Candidate of Science in Technical Sciences at the Dnipropetrovsk Mining Institute in 1966. The title of his thesis was 
"Determination of the potential of gravity and its derivatives from the measured elements of the gravitational field using computers".

In 1970 his first monograph "Determination of vertical derivatives of gravity potential according to the results of observations with horizontal gradiometer" was published. Thus he became one of the first scientists in the Former USSR who began the creation of automated systems of processing and interpretation of gravity and magnetometry data using computers. For his work "Automated system of gravimetry and magnetometry in-line processing" (in co-authorship with G.S. Butakov et al.) he was awarded the Golden Medal of the USSR Exhibition of Economic Achievements in 1972.

In 1977 Vitaliy I. Starostenko successfully defended a doctoral thesis in Moscow State University. In a year, it was further developed as a fundamental monograph "Stable numerical methods in the problems of gravimetry". Its scientific value is confirmed today by a high citation index in all publications dedicated to the problems of the theory and methods of solving ill-posed problems of geophysics.

And then, there was an intense scientific and organizational work, leadership of the influential Institute of Geophysics, where almost all the main directions of geophysics in Ukraine were developed. About the science of geophysics, Academician Starostenko wrote in an article published in the "Geophysical Journal" 2005 v. 27 No. 3: "Today's geophysics can be defined as a large, well developed division of the applied physics, that deals with the study of Earth and other planets, searches for mineral resources, solves the problems of geology, tectonics, ecology etc. using the methods of physics. Geophysics brings its invaluable contribution to the understanding of the World we live in. It uses the results of all branches of modern physics, applied mathematics (where geophysics' problems often give birth to the new directions in math ...), computer science, informatics, and technical sciences. All of the above is very interesting on itself, besides, it presents wide possibilities to choose from according to one's talents and preferences".

As already mentioned, Academician Starostenko led the Department of Earth Sciences of the $\mathrm{Na}$ tional Academy of Sciences of Ukraine. In this position, and as a member of the Presidium of NASU, he did a lot for the development of academic geo- logical science. His thought about the Academia is clearly formulated in his article published in the "Geophysical Journal" 2005 v. 27 No. 3: "Academia allows one to work creatively. In its organizational structure and life principles, refined over the centuries, there are many intelligent feedbacks that ensure a regime of self-regulation and self-organization".

And the attitude of the Academician Starostenko towards science is most clearly reflected in another paragraph of the same article: "Science is a way of life. This is an intellectual environment covering the whole world. There is less formal/superficial discipline but more internal concentration, constant (day and night, often subconscious) careful thinking about current tasks, problems, etc. Science in a sense is like sport. In both cases, it is important to keep fit, and here and there is fierce competition. This is true in all areas of life. But in science and sport, this is especially pronounced."

This inner concentration, systematicity, and self-discipline of Vitaly Ivanovich is acknowledged by everyone who collaborated or communicated with him. And the system of self-organization of work was optimized, according to Vitaly Ivanovich himself, due to doing sports (swimming) and gardening.

Beginning from 1992, there was a new stage of the development of the international scientific liaisons. The Institute of Geophysics takes part in a range of programs and projects: EUROPROBE, GEORIFT, EUROBRIDGE, PANCAPDI, DOBRE, INTAS, NARS-DEEP, IRIS, SCAR (Antarctic studies) etc.

During 1996-2002, Academician Starostenko was the member of the Scientific Committee of the International program EUROPEROBE and investigator on EUROPROBE and DOBRE projects of the International Science Fund. The results of geological and geophysical research conducted under the EUROPROBE program were published in European Union as the monograph "Structure and Dynamics of the Lithosphere of Eastern Europe", with Vitaliy I. Starostenko's participation in the editorial board. Vitaliy I. Starostenko edited many times special issues of the "Tectonophysics" journal, he was an expert of the INTAS projects. This activity of Vitaliy I. Starostenko promoted the high reputation of Ukraine in the field of geophysical investigations.

V.I.Starostenko is a member of the Specialized International Scientific Group "Gravitational 
Anomalies and Geodynamics of the Mountain Ridges", he was a co-director of the international project "Complex Geophysical Studies of the lithosphere of Central and Eastern Europe".

Prof. Vitaliy I. Starostenko's works were published not only in Ukraine but also in Russia, Austria, China, England, France, Japan, Italy, India, Netherlands, Poland, Romania, USA, Turkey, Sweden, Switzerland, former Czechoslovakia. His contacts with leading foreign scientists helped coworkers of the Institute of Geophysics to conduct investigations within the frameworks of international programs and projects.

The works of Academician Starostenko (there are more than 600) contributed to the recognition of Ukraine as a country with world-class geophysics.

Vitaliy I. Starostenko is the Editor-in-chief of the international "Journal of Geophysics" (included in the Web of Science Core Collection) and "Ukrainian Antarctic journal", the Member of the editorial board of the journal "Geology and Mineral Resources of the World Ocean".

Academician Vitaliy I. Starostenko pays much attention to post-graduate students and scientists training. There are more than 30 young scientists from Ukraine and abroad who defended their Candidate and Doctor of Sciences Theses under his supervision.

For many decades, geologists from the academic institutes have been combining the solutions of fundamental geological, geophysical problems with the search for useful minerals. In the Department of Earth Sciences of NASU, Vitaliy
Ivanovich leads the program aimed at developing the mineral resources base of Ukraine (Strategic Mineral Resources of Ukraine as the Basis for the State Security). In 2015, for the monograph with the results of the program "The Kirovograd ore area. Deep structure. Tectonophysical analysis. Ore deposits "(2013), Academician V.I. Starostenko together with O.B. Gintov and G.M. Drogitskaya became a laureate of the S.I. Subbotin Award of NASU.

And just recently, in the beginning of 2020, the staff of the Institute of Geophysics, who continue to study the lithosphere of Ukraine and neighboring territories under the direction of the Academician, received, as a symbolic gift for the Boss' jubilee, the State Prize of Ukraine in Science and Technology for their work "Deep structure of the lithosphere and seismic hazard of the territory of Ukraine".

In a short article it is impossible even to outline all aspects of the multifaceted activities of Academician Starostenko. In a reflection article on one of his anniversaries ("Geophysical Journal”, 2005 v. 27 No. 3), Vitaly Ivanovich essentially formulated his life credo "... and the main conclusion. It is necessary to work ... while you have the strength, or at least be useful to the cause and to those around you... ". To fulfill this desire, the scientific staff of the Institute of Geological Sciences, editorial board and readers of the "Geological Journal" are congratulating Academician Starostenko on his 85th birthday, wishing him good health, creative inspiration, and new successful projects. 